
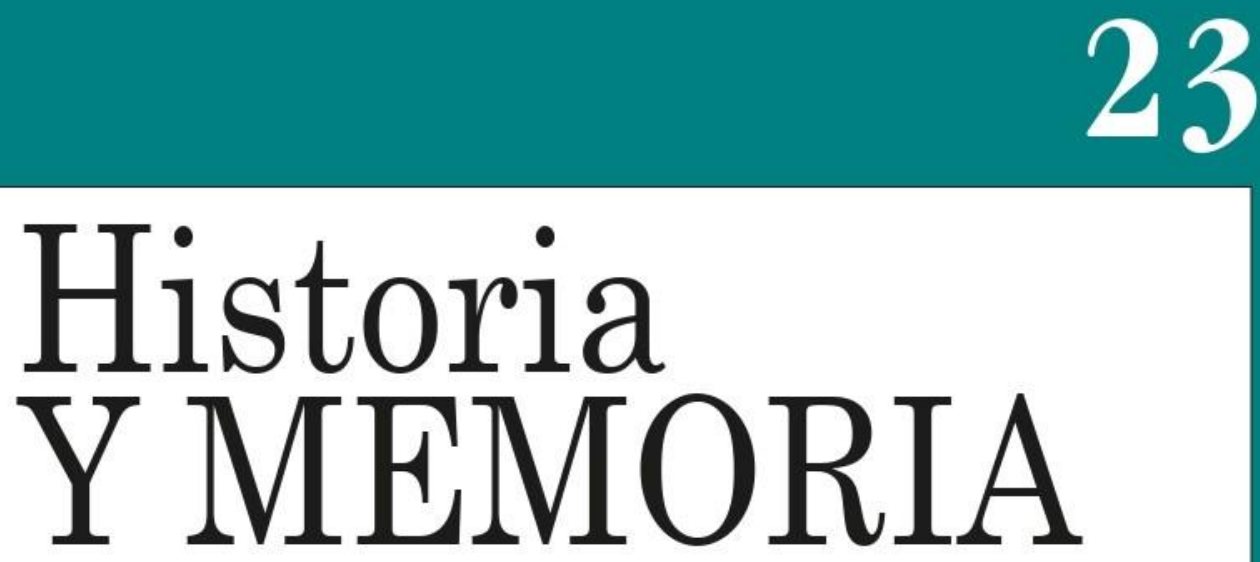

ISSN: 2027-5137 Julio - Diciembre, Año 2021 - Tunja, Colombia

La rabia en América durante el dominio español, $S$. XVI-XVIII

https:/doi.org/10.19053/20275137.n23.2021.11807

Jesús Paniagua Pérez

Páginas 57-96

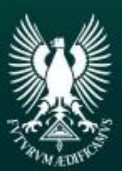




\title{
La rabia en América durante el dominio español, S. XVI-XVIII*
}

\author{
Jesús Paniagua Pérez ${ }^{1}$ \\ Instituto de Humanismo y Tradición Clásica \\ Universidad de León (España)
}

Recepción: 30/09/2020

Evaluación: 12/03/2021

Aprobación: 01/05/2021

Artículo de Investigación e Innovación

https:/doi.org/10.19053/20275137.n23.2021.11807

\section{Resumen}

La rabia o hidrofobia es una zoonosis producida por el Lyssavirus, de la familia Rhabdoviridae. Se trata de una enfermedad infecciosa, que ha preocupado desde épocas muy antiguas, por el temor que despertaba en el hombre, y que no se extinguió ni con el descubrimiento de la vacuna en 1885 . Nuestro principal objetivo es su estudio en el ámbito de la América hispana, con sus peculiaridades respecto del mundo europeo, tanto en su aparición como desarrollo y soluciones médicas y supersticiosas. Por tanto, nos interesarán, además de las manifestaciones de la enfermedad, los aspectos sociales y culturales que generaba, incluso en referencia al criollismo

\footnotetext{
* Artículo vinculado al proyecto I+D+i del Ministerio de Economía y Competitividad de España, financiado con Fondos FEDER FFI2015-65007-C4 «La herencia clásica. Descripciones y representaciones del mundo hispánico (siglos XVI-XIX)» y con la ayuda de la Junta de Castilla y León al GIR «Humanistas españoles» (LE145G18). 1 Doctor en Historia de América. Catedrático de Historia de América de la Universidad de León (España). Últimas publicaciones: «Espacios urbanos para el desarrollo de los oficios en la América hispana: el caso de la Audiencia de Quito», en Historia y Sociedad 36 (2019), 57-89. «Oficios mecánicos y cabildo en la ciudad colonial: Guayaquil en el siglo XVII», en Construyendo espacios: la ciudad iberoamericana virreinal, ed. de Jesús Paniagua Pérez y Daniele Arciello (Berlín: Peter Lang, 2020), 127-154. «Los bienes suntuarios en la Nueva Granada. La joyería masculina durante el siglo XVIII y la independencia», en Nuria Salazar Simarro y otros (México: INAH, 2020), 457-488. \jpanp@unileon.es ㄴ https://orcid.org/0000-0002-4356-6229.
} 
con la promoción de remedios puramente americanos. En consecuencia hemos utilizado una bibliografía selectiva $\mathrm{y}$ hemos consultado, bibliotecas, hemerotecas y archivos americanos y españoles, en los que hemos obtenido los materiales necesarios para llegar a unas conclusiones en que se hacen matizaciones a lo ya dicho, especialmente por los científicos experimentales, apreciando el influjo que la enfermedad tenía no solo en el individuo, sino en la sociedad que le rodeaba y en los poderes del estado, obligados a tomar decisiones acordes con el problema.

Palabras clave: Rabia, Hidrofobia, América, Siglos XVIXVIII.

\title{
Rabies in America during the Spanish dominion, 16th to 18 th centuries
}

\begin{abstract}
Rabies, historically called hydrophobia, is a type of zoonosis caused by Lyssavirus, of the Rhabdoviridae family. It is an infectious disease that has caused concern since ancient times, due to the fear that it has produced, and which did not cease despite the discovery of a vaccine in 1885 . The main objective of this article is the study of this disease in the context of Hispanic America, with its contrasts with respect to the
\end{abstract}

European world, in its origin and development, as well as its medical and superstitious solutions. Therefore, it is of interest, in addition to the manifestations of the disease, the social and cultural aspects that it generated, including, in reference to criollismo, the promotion of purely American remedies. Consequently, a selective bibliography was used and American and Spanish libraries, newspaper libraries and archives were consulted from which were obtained the necessary materials to reach some conclusions that nuance what has already been stated, especially by experimental scientists, paying attention to the influence that the disease had, not only on the individual, but also on the society around 
them, and on the powers of the state, which was forced to make decisions in accordance with the problem.

Key words: rabies, hydrophobia, America, 16th-18th centuries.

\section{La rage en Amérique latine sous la domination espagnole, XVIe-XVIIIe siècles}

\section{Résumé}

La rage ou hydrophobie est une zoonose produite par le Lyssavirus, appartenant à la famille Rhabdoviridae. Il s'agit d'une maladie infectieuse qui a inquiété l'humanité depuis longtemps et qui n'a pas disparu après l'invention du vaccin en 1885. Le but principal de cet article est d'étudier cette maladie dans l'Amérique hispanique dans ses particularités par rapport au monde européen, allant de son apparition jusqu'aux traitements médicaux et superstitieux. On s'intéressera donc aux manifestations propres à la maladie mais aussi à ses aspects sociaux et culturels, notamment à la promotion de remèdes purement américains. On a consulté des documents divers qui permettent de nuancer ce qui a été dit par les scientifiques expérimentales et qui invitent à prendre en compte l'influence de cette maladie sur l'individu et sur la société dans son ensemble, sans oublier l'État, obligé à prendre quelques décisions fondamentales en accord aux problèmes posés par la maladie.

Mots-clés: rage, hydrophobie, Amérique, $\mathrm{XVI}^{\mathrm{e}}$ et $\mathrm{XVIII}^{\mathrm{e}}$ siècles.

\section{Introducción}

«No hay enfermedad más cruel que la rabia, ni más difícil de curar», decía el Semanario de Agricultura del 29 de noviembre de 1798 , al tiempo que se creía que «entre las enfermedades 
superiores al arte y al remedio sobresale la rabia ${ }^{2}$. Se ha considerado como la peor zoonosis de la humanidad, siendo de las pocas enfermedades infecciosas que no han desaparecido después del siglo XVIII. En consecuencia, ninguna ha tenido tan mala reputación como esta, que nos aparece mencionada ya en el código Eshuma, de 2300 a.C. A partir de entonces se pueden hallar vestigios y estudios en múltiples autores, con las más variadas opiniones ${ }^{3}$. Todavía en el siglo XVII Sydeham (1624-1689) ${ }^{4}$, defensor de las teorías miasmáticas, hablaba de las influencias de las emanaciones del suelo y las aguas putrefactas. Hubo que esperar hasta Zinke y su obra Demostración de la naturaleza infecciosa de la rabia (1804) para que se ratificara que la saliva de un perro enfermo contagiaba a uno sano $^{5}$, y a Louis Pasteur para que con su vacuna solucionase los avances de una enfermedad extendida por todo el planeta. Su definición deriva de su sintomatología, lo que a su vez provocó la identificación como rabia de otros males con síntomas parecidos ${ }^{6}$. Tradicionalmente se relacionó con la teoría de los cuatro humores, que en forma de fluidos se hallan en el organismo y en concreto, por sus síntomas, con el colérico, producido por la bilis amarilla del hígado.

La importancia dada a la rabia ha estado en relación directa con la evolución del fenómeno urbano, puesto que la necesidad de salubridad, sobre todo en las ciudades, supuso controlar las enfermedades y fomentar el desarrollo de la medicina, tal como lo planteó Foucault, que utilizó el término «biopolítica» para definir el interés del estado para propiciar una vida sana y al mismo tiempo para controlar el capital

\footnotetext{
2 François Rozier, «De la rabia», en Semanario de Agricultura (Madrid, 29 de noviembre de 1798).

3 María Cristina Schneider y Carlos Santos-Burgoa, «Tratamiento contra la rabia humana: un poco de su historia», Revista de Saúde Pública, n $28-6$ (1994): 454-457. Elías Fernando Rodríguez Ferri, Rabia, riesgos y control. Análisis de la situación en España (Madrid: Consejo General de Colegios Veterinarios, 2014), 19-23. En el caso estrictamente americano.

4 Thomas Sydeham, Praxis Medica (Londres: Kneps e Innys, 1716), 180-185.

5 Georg Gottfried Zinke, Neue Ansichten der Hundswut (Jena: Fisher, 1804), 212234.

6 Osvaldo Antonio Pérez, «Ciencia y superstición. Los tratamientos contra la rabia en Sudamérica a fines del siglo XIX», Bitácora-e, $\mathrm{n}^{0} 1$ (2011): 56. Del mismo autor, Historia de la Veterinaria en el Río de la Plata (Buenos Aires, El Plata: 1994), 94.
} 
humano necesario para los avances económicos ${ }^{7}$. Esto se podría resumir en el deseo de conservación y control de la vida en función de un estado centralizado, tal y como en España lo representaron los Borbones y que, en todo el Occidente, supuso un avance de la medicina y de sus profesionales, cada vez más supeditados a ese estado ${ }^{8}$. El gobernante, por tanto y siguiendo el símil de Platón, debía actuar como quien dirige un barco, que debe ocuparse al mismo tiempo de las persona y cosas que transporta9 ${ }^{9}$ El propio Foucault planteó también que la sociedad aceptaba el problema de la salud como una responsabilidad del poder, por lo que las autoridades debían intervenir para favorecer el bien público ${ }^{10}$. La rabia, por tanto, fue otra enfermedad abordada en el siglo XVIII desde la óptica de la salubridad y el bienestar humanos propiciados por el estado, aunque en la América española, lo mismo que en la metrópoli, no se alcanzaron los niveles de otros lugares de Europa, a pesar de disposiciones como las de los bandos de buen gobierno y toda aquella normativa que se produjo con la llegada de los Borbones y muy particularmente en los reinados de Carlos III y Carlos IV.

La rabia también ha sido un tema literario del mundo americano, así en Colombia encontramos autores que la mencionan, como Boussingault, en $1824^{11}$, o más recientemente Gabriel García Márquez en Del Amor y otros demonios, novela de la que se ha dicho que confunde la melancolía con la rabia y la posesión demoníaca ${ }^{12}$. El primer autor plantea una descripción

7 Michel Foucault, «Historia de la medicalización», Educación médica y salud, $\mathrm{n}^{\circ} 11-1$ (1977): 18. Acceso el 17 de junio de 2020, https://www.terceridad.net/Sistemasdesalud/ Foucault,\%20M.\%20Historia\%20de\%20la\%20medicalizaci\%F3n.pdf; sin embargo, el término biopolítica había sido utilizado por primera vez en «El nacimiento de la medicina social», en 1977, Michel Foucault Estrategias de poder. Obras esenciales II (Barcelona: Paidós, 1999), 380.

8 Nicolas Bergasse, Lettre d'un médecin de la Faculté de Paris à un médecin du Collège de Londres (La Haya: Drukarz Nieznany, 1781), 67.

9 Michel Foucault, Seguridad, territorio, población (México: Fondo de Cultura Económica, 2006), 122-123.

10 Miche Foucault, Obras esenciales. Vol. II: Estrategias de poder (Barcelona: Paidós, 1999), 329.

11 Jean Baptiste Boussingault, Memorias (Bogotá: Banco de la República, 1985), 378-379.

12 Bienvenido Morros, "Amor y rabia en una novela de Gabriel García Márquez», Revista de Filología, n 26 (2008): 171. Acceso el 15 de junio de 2020, http://riull.ull. 
realista de una experiencia vivida personalmente y relatada en su libro de viajes, mientras que el segundo expone a través de una ficción literaria un hecho que muy bien podría responder a una realidad, pero extemporánea en la Nueva Granada, puesto que la enfermedad, como veremos, no se documenta hasta principios del siglo XIX, mientras la trama se desarrolla en el siglo anterior; sin embargo, Márquez también introduce datos reales en su novela como los precedentes, las creencias y los remedios de la época, las matanzas de perros, etc.; incluso recurre a figuras prosopográficas para describir los síntomas de la enfermedad ${ }^{13}$.

Nuestra hipótesis de trabajo consiste en averiguar cómo la sociedad americana desarrolló el miedo frente a las enfermedades contagiosas a través del estudio histórico de la rabia, un mal en el que se mezclaban connotaciones de religiosidad popular con el pánico por unos síntomas que provocaban el más absoluto rechazo psicológico, sin que por ello fuera la más letal entre las enfermedades de la época. Asimismo, es nuestro interés relacionar su presencia tardía en América, al menos en términos cuantitativos y de expansión, con los avances en las comunicaciones marítimas del siglo XVIII y con la llegada de perros contagiados, principales agentes transmisores. Todo esto nos debería conducir a establecer una relación con la racionalidad científica, que se mezcló con frecuencia en determinados ámbitos con la superstición y que, al mismo tiempo, sirvió para probar la intervención del poder en el ámbito de salud como manifestación del despotismo ilustrado (biopolítica) ${ }^{14}$. En la América hispana, el avance de la enfermedad se podría vincular igualmente al auge del criollismo, pues en la medida en que se consideraba como un mal europeo incurable se le buscaron remedios americanos.

Ala luz de ello, al estudiar el desarrollo de esta enfermedad en la época colonial, hemos optado preferentemente por fuentes

es/xmlui/handle/915/14203.

13 Gabriel García Márquez, Del amor y otros demonios (Buenos Aires: Sudamericana, 1995), 12-16, 32.

14 Michel Foucault, Nacimiento de la biopolítica: Curso del Collège de France (19781979) (Barcelona: Akal, 2012), 71-72, 311-312. 
de la época, tanto las bibliográficas como las documentes del Archivo General de Indias y de algunos archivos nacionales, especialmente a las referencias sanitarias que en cada archivo pueden ocupar secciones de diferente denominación; así como a las publicadas (crónicas, libros de viajes, libros técnicos de veterinaria y medicina, obras religiosas y literarias) y a exposiciones teóricas sobre la enfermedad, especialmente de Foucault y de especialistas en historia de las enfermedades infecciosas. Para nosotros han tenido una especial relevancia las hemerotecas por la aportación de datos precisos y contemporáneos a los hechos, especialmente coincidiendo con el periodo ilustrado, ya que con anterioridad existen dudas sobre si realmente la enfermedad tuvo alguna trascendencia más allá de meras especulaciones que la relacionaban con las fuerzas del mal. A partir de los datos obtenidos, teniendo en cuenta también aspectos cronológicos (la época de dominio español y de manera especial el siglo XVIII) y geográficos (el continente americano), elaboramos el presente estudio.

\section{Sobre la enfermedad y su presencia en América}

La rabia se transmite generalmente por la mordedura de animales infectados, principalmente perros (rabia urbana), aunque en el caso americano también fueron fundamentales los quirópteros (Desmodus rotundus $)^{15}$, y otros animales, especialmente del ámbito rural (rabia silvestre) ${ }^{16}$. Una vez inoculado el virus, este altera el sistema nervioso, ya que pasa rápidamente a la medula espinal y al cerebro, produciendo serias alteraciones, por lo que se relacionaba directamente con las enfermedades nerviosas.

Los síntomas aparecen entre los dos y los diez días con el auto-aislamiento, falta de hambre y sed, vómitos y cefaleas; después llegan la hidrofobia y las alucinaciones, para acabar

15 Aurelio Málaga Alba, «Vampire bat as a carrier of rabies», American Journal of Public Health, $\mathrm{n}^{\circ} 44$ (1954): 909-918. Elmer Escobar, «La rabia transmitida por vampiros», Biomédica vol. 24, n 3 (2004): s/p, doi: https://doi.org/10.7705/biomedica. v24i3.1268.

16 Félix de Azara, Viajes por la América del Sur (Montevideo: Comercio del Plata, 1850), 178. 
inexorablemente con la muerte; síntomas reflejados en la obra de Pérez Escobar ${ }^{17}$. El periodo de infección se sitúa entre 2140 días, es decir, menos de lo que solía durar el viaje a las Indias, que se calculaba en unos 40 días hasta Santo Domingo y otros 20 días hasta Veracruz. Esto implicaba que un animal o persona infectada moría en el trayecto y era arrojado al mar antes de llegar al Nuevo Mundo.

La literatura científica de la época, debido al desconocimiento profundo de la enfermedad, no siempre la consideraba letal. De su mortalidad se culpó, a veces, al propio descuido de quienes la padecían, que acudían demasiado tarde a los hospitales, como se menciona en el de San Pedro de Puebla, donde se dice que disponían de las medicinas necesarias, incluidas las más costosas ${ }^{18}$. En tal sentido no debe olvidarse que los hospitales, controlado por la Iglesia incluso en el siglo XVIII, de alguna manera, representaban el abandono del enfermo que carecía de recursos o, como manifiesta Foucault, el lugar en el que, hasta el siglo XVIII, ingresaba para morir quien no disponía de recursos para contratar los servicios de un médico, por lo que estos lugares representaban al mismo tiempo un efecto positivo (cuidados) y negativo (la inevitable muerte) ${ }^{19}$, pero su fin esencial no era la curación, sino la asistencia a los pobres ${ }^{20}$. La presencia del médico al frente de los mismos en el siglo XVIII cambió la situación y dio lugar a una normatividad propia de la medicina clínica, que permitía ampliar los conocimientos desde la praxis médica ${ }^{21}$; esto, en el mundo hispánico tuvo muchas limitaciones, puesto que el control religioso se siguió manteniendo, aunque es cierto que se introdujeron algunas novedades, como mencionaremos, especialmente en la farmacología, o la aparición de los

17 Antonio Pérez de Escobar, Avisos médicos, populares, y domésticos. Historia de todos los contagios (Madrid: Ibarra, 1776), 115.

18 «Resumen de los enfermos que entran a curarse en el Hospital General de San Pedro Apóstol», Gazeta de México, México, 13 de marzo de 1802, 26.

19 Michel Foucault, "La crisis de la medicina o la crisis de la antimedicina», en Medicina e historia. El pensamiento de Michel Foucault, ed. Miguel Márquez (Washington: Organización Panamericana de la Salud, 1978), 23.

20 Michel Foucault, «Incorporación del hospital en la tecnología moderna», Educación médica y salud, n 12-1 (1978), 23.

21 Foucault, «Incorporación del hospital...», 12. 
hospitales militares como germen de la novedad de la atención hospitalaria, siguiendo el modelo francés ${ }^{22}$.

Se pensaba igualmente que el momento propicio para la expansión era la canícula, porque en ella dominaba la estrella Perro o Sirio, la más grande de la constelación Can Mayor, lo que implicaba sequedad y calor; es decir, existía una idea astral y de determinismo climático ${ }^{23}$; por ello en Cuba, en 1826 , se ordenaba poner recipientes con agua por las calles ${ }^{24}$. Aquella apreciación se vio reflejada, por ejemplo, en Quevedo:

El piélago encendido está exhalando

al sol humos en traje de vapores;

$y$, en el cuerpo, la sangre y los humores

discurren sediciosos fulminando ${ }^{25}$.

Frente a lo mantenido tradicionalmente, existe en las últimas décadas una tendencia a considerar que la rabia ya existía en América antes de la llegada de los españoles y tendría como agentes propagadores a los quirópteros, aunque con una capacidad de expansión mucho menor que la europea y sin la seguridad total de una transmisión de la hidrofobia, que para Koprovsky habría que tener en cuenta desde el siglo $\mathrm{XVI}^{26}$. Los vestigios se han buscado en algunos cronistas; así Fernández de Oviedo mencionaba unos pájaros nocturnos: «E digo que en Tierra Firme hay muchos dellos, que fueron muy peligrosos a los cristianos a los principios que aquella tierra pasaron con el adelantado Vasco Núñez de Balboa y con el bachiller Enciso» ${ }^{27}$. Molina Solís, al relatar la conquista de Yucatán por Montejo, en 1527, cuenta que «cayó sobre ellos

22 Foucault, «Incorporación del hospital», 24-25.

23 Pedro Ciruelo, Reprobaciones a las supersticiones y hechicerías (Valladolid: Maxtor, 2005), 94.

24 Francisco Dionisio Vives, Bando de buen gobierno adicionado (La Habana: Fraternal, 1828), 41.

25 Francisco de Quevedo, Poesía metafísica y amorosa (Barcelona: Planeta, 1976), 58 .

26 Miguel Cordero del Campillo, Crónicas de Indias. Ganadería, medicina y veterinaria (Valladolid: Junta de Castilla y León, 2001), 179-181.

27 Gonzalo Fernández de Oviedo, Sumario de la natural y general historia de las Indias (México: Fondo de Cultura Económica, 1950), 220. 
gran plaga de murciélagos que atacaron, no solamente a las bestias de carga, sino a los hombres mismos, chupándoles la sangre mientras dormían ${ }^{28}$. Lo anterior se ha relacionado también con la creencia maya de que las enfermedades eran causadas durante la noche por espíritus con forma animal, así como con la existencia de la palabra «coil», equivalente a «rabia», utilizada en el Ritual de los Bacbas, que, aunque es un manuscrito del siglo XVIII, recoge noticias anteriores ${ }^{29}$. Tampoco se descarta que fuera conocida en otros lugares del continente, pues entre los guaraníes existía un término para denominar a esta enfermedad, tumbi-baba ${ }^{30}$. En realidad, y a pesar de lo dicho, se sigue careciendo de una casuística concreta que corrobore tal existencia ${ }^{31}$.

La opinión más extendida mantiene que la rabia fue una aportación de los europeos. Gómara negaba su existencia en las Indias, ya que no existían una serie de animales, entre ellos los perros del Viejo Mundo ${ }^{32}$. En 1591, Juan de Cárdenas reconocía que no había visto rabiar a los animales, porque no se daban las causas que producían la enfermedad, como destemplanza del aire, sed, hambre, fatiga, cansancio y comidas muy calientes ${ }^{33}$. Juan y Ulloa en el siglo XVIII tampoco admitían la existencia prehispánica de la enfermedad ${ }^{34}$.

28 Juan Francisco Molina Solís, Historia del descubrimiento y conquista del Yucatán III (Mérida de Yucatán: Mensaje, 1943), 38.

29 Se trata de un documento que aparece con la firma del supuesto autor y cuya versión en inglés se debe a David Bolles. Joan Canul, Ritual de los bacbas (Lancaster: Labyrinthos, 2003). 88

30 Alberto I. de Diego y Jorge R. Valotta, «Rabia transmitida por murciélagos», Boletín de la Oficina Sanitaria Panamericana, no 86-6 (1979), 495, acceso el 18 de junio de 2020, https://iris.paho.org/handle/10665.2/17296.

31 A. Vos y otros, «The occurrence of rabies in pre-Columbian Central America: an historical search", Epidemiology and Infection, $\mathrm{n}^{\circ} 10$ (2011): 1445-1452, doi: dx.doi.org/10.1017/S0950268811001440 H. Badrane y N. Tordo, «Host switching in Lyssavirus history from the Chiroptera to the Carnivora orders», Journal of Virology, $\mathrm{n}^{\mathrm{o}} 75$ (2001): 8096-8104, doi: https://doi.org/10.1128/JVI.75.17.8096-8104.2001

32 Francisco López de Gómara, Historia general de las Indias I (Caracas: Ayacucho, 1979), 280-281.

33 Juan de Cárdenas, Primera parte de los problemas, y secretos maravillosos de las Indias (México: Pedro Ocharte, 1591), 223v-228v.

34 Jorge Juan y Antonio de Ulloa, Relación histórica del viaje a la América Meridional (Madrid: Antonio Marín, 1748), 214. 
La presencia generalizada, por lo que hasta ahora sabemos, no se produciría hasta el siglo XVIII, aunque puede que fuese anterior, pues en 1667, Du Tertre, al describir Saint-Domingue, mencionaba una enfermedad terrible de los perros en las Indias ${ }^{35}$. Es probable que el autor usase el nombre genérico de Indias, pero que se refiriera solamente a las islas francesas del Caribe, lo que nos haría pensar que esa misma enfermedad estaría presente en la parte española de Santo Domingo.

Lo cierto es que con el inicio del siglo XVIII la rabia comenzó a propagarse. La velocidad náutica había hecho que el Atlántico dejase de ser una barrera sanitaria de contención ${ }^{36}$. Lejos quedaba la idílica imagen que en este sentido nos describía uno de los poemas del jesuita Rodrigo Valdés:

\author{
Praeservan de contagiosa \\ Peste regiones tan sanas, \\ quae ignoran canes rabiosos, \\ si canes syrios contrastan (sic) ${ }^{37}$.
}

Fueron entonces apareciendo los focos de contagio, con unas fechas que repiten los autores, pero de las que haremos algunas correcciones: Nueva España (1709), Antillas (1719), Barbados (1741), las Trece Colonias (1753), Saint-Domingue (antes de 1776, aunque probablemente ya en el siglo XVII), Jamaica, Guadalupe y Haití (1783), Perú (1803), Argentina (1806), Uruguay (1807), Colombia (1810), Saint-Maurice (1813), Canadá (1819), Chile (1835), Puerto Rico $(1838)^{38}$.

35 Jean Baptiste du Tertre, Histoire generale des Antilles habitées par les François (París: Thomas Iolly, 1667), 307.

36 Miguel Ángel Márquez Ruiz, «El intercambio de patógenos entre el Viejo y el Nuevo Mundo, los casos de la rabia y del moquillo canino», Revista del Colegio de Médicos Veterinarios del estado Lara, $\mathrm{n}^{\circ} 1-2$ (2011), s/p.

37 Rodrigo de Valdés, Poema heroyco hispano-latino panegyrico de la fundacion, y grandezas de la muy noble, y leal ciudad de Lima (Madrid: Antonio Romás, 1687), 76. 38 A.A. King y otros, Historical Perspective of Rabies in Europe and the Mediterranean Basin. A testament to rabies by Dr Arthur A. King (Paris: World Organisation for 
A partir de esas fechas iniciales, en cada lugar la expansión no se detuvo. En Nueva España fue en 1709 cuando Marmolejo mencionaba una loba con hidrofobia en Mellado (Guanajuato) $^{39}$. Era un solo caso, pero el miedo se filtró en la sociedad, hasta el punto de que en ese año se publicó la novena a santa Quiteria, mientras Steyneffer pensaba que era solo un problema de aquel virreinato ${ }^{40}$. Precisamente en México, Málaga Alba adelanta esa presencia de la rabia hasta $1703^{41}$.

El siguiente foco estaría en Cuba, en Villa de Remedios (1719), a partir del cual los sucesos de hidrofobia se fueron repitiendo en diferentes lugares de la isla, y muy especialmente en La Habana, donde en 1725 hubo una verdadera plaga entre los perros de la ciudad ${ }^{42}$, generando lo que se ha denominado, de acuerdo con una expresión de Foucault, «los pequeños pánicos», que según dicho autor eran propios del mundo urbano y especialmente de la burguesía de las grandes ciudades del siglo XVIII europeo ${ }^{43}$, pero también de algunas americanas como La Habana ${ }^{44}$.

La llegada a Sudamérica fue más tardía y, todavía en 1777 , se mantenía que no se habían detectado perros rabiosos. El primer foco debió ser la Nueva Granada, donde en 1794 se daba una providencia en Santafé para evitar el mal. En Cartagena, la fecha tradicional de aparición de la rabia en

Animal Health, 2004), 262. Márquez Ruiz «El intercambio de patógenos,» s/p.

39 Lucio Marmolejo, Efemérides guanajuatenses, o, datos para formar la historia de la ciudad de Guanajuato II (Guanajuato: Universidad de Guanajuato, 1971), 12.

40 Juan de Steyneffer, Florilegio medicinal (Ámsterdam: Oosterwiyck, 1719), 383385 .

41 Málaga Alba, «Vampire bat,» 909-918.

42 José A. Martínez-Fortún Foyo, Epidemiología: síntesis cronológica (La Habana: Ministerio de Salubridad, 1952), 29, 42. Anónimo, «Siglo XVIII (1701-1750) Panorama histórico dominante», Cuadernos de Historia de la Salud Pública, $\mathrm{n}^{\circ} 96$ (2004): sp. Acceso el 20 de abril de 2021, http://www.habanaelegante.com/Winter2004/Panoptico. html

43 Foucault, «Historia de la medicalización...», 12 .

44 «Marqués de Armas, Pedro L. Panóptico habanero», Habana Elegante, acceso el 18 de junio de 2020, http://www.habanaelegante.com/Winter2004/Panoptico.html. 
1810 no parece que sea la correcta, pues la enfermedad ya estaba presente entre 1800-1804 ${ }^{45}$.

En Perú, en 1803, desde los valles costeros del norte se había expandido hacia el sur, dejando en Ica hasta 43 muertos, mientras que en Lima los contagiados lo fueron en las chacras y los valles del entorno. Esta epidemia se repetiría en 18071808, afectando sobre todo a Arequipa, donde residía el prestigioso médico Zoldi Rosas y donde llegó en esos momentos José Salvany con la vacuna de la viruela, ayudando a combatir la epidemia ${ }^{46}$, a pesar de su precaria salud ${ }^{47}$. Allí el proceso se repetiría en los años 1813, 1821 y $1829^{48}$. Afortunadamente, en este caso tenemos el relato de un científico y médico como Unanue, que definió aquella hidrofobia como espontánea, puesto que animales y personas la sufrieron sin mordeduras previas, achacando la causa al calor de los años 1803-1804 ${ }^{49}$.

Caso peculiar fue el del Río de la Plata, donde la enfermedad llegó y se expandió por medio de los perros que desde Europa y Sudáfrica llevaron los británicos en la invasión de 1806, lo mismo que sucedería al año siguiente en la Banda Oriental ${ }^{50}$. Con un afán nacionalista, tras la independencia, la prensa incidió en la culpabilidad europea y se comparó a los

45 «Perros, rabia», Cartagena, 1785-1804, Archivo General de la Nación (AGN), Bogotá-Colombia. Sección Miscelánea: SC.39.112,D.29, ff. 281-282.

46 Bartolomé María Salamanca, "Arequipa. Relación de Gobierno», Boletín de la Sociedad Geográfica de Lima, no 10 (1901): 230-231. Rafael Cordero-Moreno, Compendio de la historia de la medicina en Venezuela (Caracas: Universidad Católica Andrés Bello, 1998), 56.

47 «Certificado médico de Salvany», Arequipa, 17 de diciembre de 1807, Archivo General de Indias (AGI), Sevilla-España. Sección Indiferente General 1558A.

48 Juan Torres Guevara, «El clima y los ecosistemas», en Historia ambiental del Perú. Siglos XVIII y XIX, ed. Julio Díaz Palacios y otros (Lima: Ministerio del Ambiente, 2016), 98.

49 Hipólito Unanue, Observaciones sobre el clima de Lima, y sus influencias en los seres organizados, en especial el hombre (Madrid: Imprenta de Sancha, 1815), 67-69.

50 Carlos Francisco Amasino, C. J. Garbi y M. F. Amasino, «La rabia urbana en la provincia de Buenos Aires, Argentina: origen-evolución-actualidad», Analecta Veterinaria, $\mathrm{n}^{\circ}$ 22-1 (2002): 23. Acceso el 12 de marzo de 2021, http://sedici.unlp.edu. ar/handle/10915/11141. Harald Norlin Johnson, «Rabies», en Viral and Rickettsial Infections of Man, ed. Thomas M. Rivers y Frank L.Horsfall Jr. (Filadelfia: Lippincott, 1959), 17-18. 
enfermos con Acteón despedazado por los perros ${ }^{51}$. En Buenos Aires habría un rebrote en $1810^{52}$.

De otros lugares no tenemos noticias tan precisas. En Costa Rica se conocen casos de rabia en 1830, en que el presidente mandó decir una misa solemne como se había hecho en 1733, cuando la rabia apareció en la ciudad de Cartago ${ }^{53}$; aunque hay quien la menciona ya en $1714^{54}$. También en los territorios quiteños pudo extenderse la enfermedad, a pesar de lo manifestado por Juan y Ulloa, pues en Guayaquil, en la segunda mitad del siglo, la rabia se mencionaba como una de las enfermedades urbanas ${ }^{55}$. En Chile, cuando Darwin visitó Copiapó, en 1835, relató la epidemia en un valle, donde no era la primera vez que esto sucedía ${ }^{56}$.

En América del Norte se generalizó sobre todo a partir de la segunda mitad del XVIII, especialmente en la zona atlántica y de manera muy especial en Massachusetts y Maryland ${ }^{57}$. La Gaceta de Madrid del 17 de julio de 1822 informaba que en Filadelfia y Nueva York la hidrofobia causaba grandes estragos y los soldados tenían orden de matar a los perros en las calles. En Canadá la epidemia de 1819 le costó la vida al propio gobernador, el duque de Richmond ${ }^{58}$.

\section{Los agentes de transmisión. Los perros en el punto de mira}

51 «Rabia,» La Abeja Argentina, Buenos Aires, 15 de mayo de 1822, 72-73.

52 Antonio L. Turnes, Bernardo Porzecanski y su lucha contra la rabia en el Uruguay (Montevideo: Granda, 2014), 91. "Gran Bretaña», Gaceta de Madrid, Madrid, 26 de octubre de 1819, 1085.

53 Esteban Rodríguez Dobles, «Discordias teóricas de la historia de las mentalidades colectivas, aportes, conceptos y problemas», Reflexiones, $\mathrm{n}^{\circ}$ 84-1 (2005): 18.

54 José Luis Beltrán, Historia de las epidemias: en España y sus colonias (13481919) (Madrid: Esfera de los Libros, 2006), 101.

55 Enrique Garcés, Eugenio Espejo, Médico y duende (Quito: Casa de la Cultura Ecuatoriana, 1959), 272-273.

56 Charles Darwin, Viaje de un naturalista alrededor del mundo (Madrid: Verbum, 2020), 294-295.

57 Víctor Babes, Traité de la rage (París: Bailliere et fils, 1912), 23-24.

58 S.A. Nadin-Davis y J. Bingham, «Europe as a Source of Rabies for the Rest of the World», en Historical Perspective of Rabies in Europe and the Mediterranean Basin, ed. A.A. King y otros (París: World Organisation for Animal Healt, 2004), 262. 
Aunque son muchos los animales que pueden transmitir la rabia, los perros son los agentes por excelencia. Las razas que llegaron del Viejo Mundo lo hicieron paralelamente con las personas ${ }^{59}$; sin embargo, nada indica que llegasen rabiosos, aun coincidiendo con un momento de auge de la enfermedad en España. De haber sido así, la hidrofobia se habría expandido inexorablemente, toda vez que muchos de estos animales se utilizaron para intimidar a los indios y a los esclavos, a pesar de las órdenes de la Corona para evitarlo, como las enviadas ya a Nicolás de Ovando a La Española ${ }^{60}$ o a Vaca de Castro al Perú ${ }^{61}$. Estas órdenes solían ir asociadas al sacrificio de los «perros carniceros», como en Popayán, en $1565^{62}$; sin embargo, era habitual incumplirlas como sucedió en Santafé $^{63}$ o en Antioquia ${ }^{64}$. En el siglo XVIII incluso se adiestraban perros en Cuba, que compraban los británicos para la «caza» de esclavos $^{65}$.

Fue a partir del siglo XVIII, con la expansión de la enfermedad, cuando estos animales fueron considerados un auténtico peligro, especialmente los que deambulaban sin dueño. Con ello, el temor de la población aumentaba y se era muy susceptible al peligro, como sucedió, por ejemplo, en un barrio de Lima, donde un habitante solicitó al virrey el sacrificio de dos perros bravos que le habían atacado ${ }^{66}$. Los

59 Alfredo Bueno Jiménez, «Los perros en la conquista de América: historia e iconografía», Chronica Nova 37, (2011): 177-204. Acceso el 18 de abril de 2020, http:// hdl.handle.net/10481/20359.

60 «Que se eviten los daños de los perros a los indios», Segovia, 27 de noviembre de 1503, Archivo General de Indias (AGI), Sevilla-España. Sección Indiferente, 418, L.1, f. $119 \mathrm{v}$.

61 «Real provisión al licenciado Vaca de Castro», Fuensalida, 7 de octubre de 1541, Archivo General de Indias (AGI), Sevilla-España. Sección Lima 566, L.4, f. 242v.

62 «Muerte de perros feroces», Bosque de Segovia, 21 de agosto de 1565, Archivo General de Indias (AGI), Sevilla-España. Sección Quito, 215, L.1, f. 45.

63 «Pleito por ataque a indios», Santafé 1618, Archivo General de la Nación (AGN), Bogotá-Colombia. Sección Caciques_indios,1,D.11, ff. 147-158.

64 "Alférez real desobedece las órdenes sobre no tener perros bravos», Antioquia, 1796, Archivo General de la Nación (AGN), Bogotá-Colombia. Sección Milicias y Marina, CO.AGN.SC.37.130.26, ff. 80-87.

65 «Gobernador Habana, sobre llegada de un comisionado», La Habana, 1 de abril de 1796, Archivo General de Indias (AGI), Sevilla-España. Sección Estado, 5B, N.172. 66 «Extinción de perros», Lima, diciembre de 1810, Archivo General de la Nación (AGN), Lima-Perú. Sección Secretaría de Cámara del Virrey, GO_BI_BI1_057, f. 
temores, por tanto, exigían un remedio. La solución más habitual pasó por el "sacrificio» de los agentes, de acuerdo con las ideas ilustradas de salubridad, ya que la higiene pública se convirtió en un fin del buen gobierno, facilitando y controlando la salud de los individuos ${ }^{67}$. En tal sentido, no hay que olvidar las sugerencias sobre la rabia de Foronda, que en 1781 recomendaba aplicar en los reinos hispánicos las que regían para París ${ }^{68}$. Lo cierto es que varios bandos de buen gobierno tocaron el tema, especialmente en el Caribe.

Precisamente los cabildos y otras instituciones, ante la amenaza, pusieron su acento en las matanzas de perros, que se hicieron comunes. En la ciudad de México, en 1779, los regidores las justificaron por «las fatalidades que frecuentes se ven y oyen de los perros, con muertes, mordidas y rabia, dejando a muchos lisiados y lacrados, no habiendo casa en que no se encuentre algún mordido» ${ }^{69}$. Igualmente, en 1790, el virrey, motivado por sus fines modernizadores de la ciudad, ordenó una matanza que afectó a 20.000 de aquellos animales ${ }^{70}$.

La misma actividad encontramos en el virreinato de Nueva Granada. En 1793 se favoreció en Santafé de Bogotá el sacrificio de los perros en las calles, utilizando para ello «matadores» oficiales. El problema no parece haberse solucionado, pues en 1798 el cabildo prohibía criar y mantener perros dentro de la ciudad y sus arrabales por los daños que podían causar, so pena de ser sacrificados ${ }^{71}$. Con todo, un lugar especialmente amenazado debía ser Cartagena, donde se recuerda que en 1800 se había sacado a los forzados del presidio para acabar con los perros, lo que se repitió en $1804^{72}$. En Medellín, en 1808, el

1119.

67 Foucault, «Historia de la medicalización», 18.

68 Valentín de Foronda, Cartas sobre la policía (Madrid: Cano, 1801), 38-45.

69 Arnaud Exbalin Oberto, «Perros asesinos y matanzas de perros en la ciudad de México (siglos XVI-XVIII)», Relaciones, ${ }^{\circ} 137$ (2014): 100.

70 Exbalin Oberto, «Perros asesinos», 106.

71 «Prohibición crianza de perros», Santafé, 7 de mayo de 1798, Archivo General de la Nación (AGN), Bogotá-Colombia. Sección Miscelánea: SC.39,95,D.70, ff. 686-687.

72 «Perros rabia», Santafé, 1785-1804. Archivos General de la Nación, BogotáColombia. Sección Miscelánea:SC.39,112,D.29, ff. 281-282. 
procurador general ordenó el exterminio, pues por la rabia se ponía en peligro la salud de los habitantes ${ }^{73}$. En Antioquia, el 4 de septiembre de 1816, el gobernador permitía la matanza de los perros callejeros, por estar contaminados de hidrofobia, añadiendo otra causa económica, proteger al ganado lanar, del que dependía parte de su desarrollo ${ }^{74}$.

En Perú, ante el brote de rabia de 1803, el virrey Abascal mando hacer una matanza de perros en Lima ${ }^{75}$. En 1807, por el mismo motivo, se realizó otra en Arequipa, que incluyó también a los gatos ${ }^{76}$.

En el Río de la Plata se nos plantean problemas sobre la fecha tradicional aceptada para la epidemia (1806), puesto que ya en 1762 se había ordenado a los criadores de ganado una cacería de perros cada cuatro meses, lo que se repitió en 1790, con batidas que siguieron reproduciéndose hasta 1806, cuando de forma efectiva hizo aparición la rabia ${ }^{77}$; así, por ejemplo, en 1796 en San Luis y en 1800 en La Luz se había ordenado una aniquilación, permitiendo mantener a uno por casa, pero atado ${ }^{78}$. Es cierto que no se menciona la rabia como causa hasta la invasión británica, pero nos queda la sospecha de que pueda haber sido uno de los motivos de las matanzas, además del ataque a las reses. Posteriormente, en 1820, el gobierno bonaerense organizó una correría con el ejército, en que se sacrificaron un buen número de perros, pero los soldados se negaron a repetirlo, puesto que en la ciudad se les había comenzado a denominar como «mataperros». Otro

73 Adriana Alzate Echeverri, Suciedad y orden: reformas sanitarias borbónicas en la Nueva Granada 1760-1810 (Bogotá: Universidad del Rosario, 2007), 115-116.

74 «Bandos del gobernador de Antioquia», Medellín, 4 de septiembre de 1816, Archivo General de la Nación (AGN), Bogotá-Colombia. Sección Historia: SAAI.17,21,D.50, f. 384 .

75 Unanue, Observaciones..., 67-69.

76 Salamanca, «Arequipa», 231.

77 María Dolores Pérez Baltasar, «Buenos Aires, un ejemplo de urbanismo ilustrado» (Tesis de doctorado, Universidad Complutense de Madrid, 2015), 203-204. 78 Víctor Tau Anzoátegui, Los bandos de buen gobierno del Río de la Plata, Tucumán y Cuyo: (época hispánica) (Buenos Aires: Instituto de Investigaciones de Historia del Derecho, 2004), 73, 527. 
exterminio se produjo en 1826, después de que uno mordiese al caballo del presidente Bernardino Rivadabia ${ }^{79}$.

En 1807 el gobernador de Montevideo ordenó una limpieza de perros por los acuciantes problemas de la rabia, que había causado la muerte de 10 personas ${ }^{80}$. El cabildo del 5 de octubre de 1807 tomó varias medidas en este sentido. Los estancieros deberían hacer matanzas periódicas, cuyas colas debían entregar a las autoridades para comprobar la ejecución de la orden; las matanzas se extendían a las chacras, mataderos y saladeros del entorno de la ciudad, donde en las casas se permitía un máximo de dos perros, debiendo sacrificarse el resto, excepto si se trataba de "casta fina, los de aguas, los de perdices y los de presa que sirven para el resguardo de la casa", pero siempre mantenidos con bozal. Aquellas matanzas se repetían periódicamente, pero, aunque el motivo era la rabia extendida por el agro, esta no se menciona ${ }^{81}$, como sí lo hizo el delegado Nicolás Delgado, en su viaje a Paysandún ${ }^{82}$.

En las islas del Caribe, tras aquellos tempranos brotes que mencionamos, Cuba ofrecía una visión desoladora de perros abandonados y hambrientos, que infectaban a las reses que servían para el consumo ${ }^{83}$. La situación se achacó a la sequía de 1826, por lo que se ordenó una matanza, alegando que aquello se hacía por el bien de la humanidad y por el propio de los cubanos ${ }^{84}$. En Puerto Rico, el 13 de abril de 1775, el ayuntamiento de San Juan convocó a los negros lanceros

79 «Perros cimarrones», Revisionistas la otra historia de los argentinos, acceso el 27 de junio de 2020, http://www.revisionistas.com.ar/?p=7429.

80 Azara, Viajes, 169.

81 Turnes, Bernardo Porzecanski..., 90-92. Gregorio Daniel Brejov, «Perros de los conquistadores y cimarrones», Revista Veterinaria Argentina (abril 2020): s/p. Acceso el 23 de mayo de 2020, https://tinyurl.com/y3wjkapr.

82 Dámaso Antonio Larrañaga, Diario del viaje de Montevideo a Paysandu (Montevideo: Instituto Nacional del Libro, 1994), 42-51.

83 Francisco Dionisio Vives, Cuadro estadístico de la siempre fiel isla de Cuba, correspondiente al año de 1827 (La Habana: Oficina de las viudas de Arazoza y Soler, 1829), 46.

84 Francisco Dionisio Vives. "Bando de buen gobierno, adicionado por el excelentísimo señor...", en Los bandos de buen gobierno en Cuba: la norma y la práctica (1730-1840), ed. Dorleta Apaolaza Llorente (Vitoria: Universidad del País Vasco, 2016), 568. 
de cangrejos para que realizasen una matanza «de perros, cerdos y otros animales perjudiciales al bien común y sobre que se experimenta un grande exceso principalmente en la abundancia de perros» ${ }^{85}$.

Estas matanzas organizadas por las autoridades nos están indicando que cada vez más la salud se estaba convirtiendo en un problema del estado, cuyos representantes con frecuencia actuaban como autoridades médicas más allá de sus propios conocimientos sobre la materia, pues la sanidad superaba el ámbito exclusivo de la enfermedad por las consecuencias que esta tenía en otros ámbitos. Esto explicaría que en las matanzas que hemos descrito se aprecie que, con cierta frecuencia, se recurría al ejército para el control de la enfermedad.

\section{Ciencia y superstición. Información y curaciones}

Aunque en el siglo XVIII se decía que de pocas enfermedades se había escrito tanto ${ }^{86}$, el nulo o escaso desarrollo de la enfermedad en América hasta entonces no favoreció la atención de los estudiosos de aquellas tierras, mientras en la metrópoli eran muchos los que trataron sobre la hidrofobia, como Andrés Laguna, Luis de Lemos, Miguel de Heredia, Matías García, etc. Incluso se escribió algún tratado expreso como el De hidrofobia natura causis de Juan Bravo de Piedrahita, de 1571, y algún albéitar emitió su opinión, situando el origen de la enfermedad en los malos vapores que suben del estómago a la cabeza de los animales ${ }^{87}$. Todo ello sin olvidar múltiples autores europeos entre los que podemos destacar a Francastoro, quien primero describió con precisión la enfermedad, en su obra de 1546 De contagione et contagiosis morbis, negando la transmisión

85 César Augusto Salcedo Chirinos, «El perro como problema sanitario: Higiene y gobierno urbano en el Puerto Rico del siglo XIX», Revista de Ciencias y Humanidades, $\mathrm{n}^{\circ}$ 10-10 (2020): 258-259. Acceso el 18 de junio de 2020, https:// revistacienciasyhumanidades.com/index.php/home/article/view/112.

86 Bartolomé Piñera y Siles, discurso del traductor a Disertación acerca de la rabia espontánea, de Laurent Charles Pierre Le Roux (Madrid: José Doblado, 1786), 8.

87 Fernando Calvo, Libro de Albeyteria: en el qual se trata del cavallo y mulo, y Iumeto, y de sus miembros y calidades y de todas sus enfermedades (Salamanca: Juan Fernández, 1587), 119v-120. 
por contacto y avalando la de mordedura. En el setecientos fue cuando surgió un verdadero interés por el estudio de la hidrofobia en función del desarrollo de la salud pública y de aquella máxima ilustrada de la felicidad de los hombres, que condujo al interés por el control de las epidemias y con ello de la población.

En la metrópoli abundaron los tratadistas que tocaron el tema, como Francisco de Vallejo (1752), José Santeli (1755), Josef Antonio Capdevila (1787), Juan Antonio Montes (1789), Antonio Pérez Escobar (1776), Juan Galisteo (1776), Segismundo Malats (1800), Joaquín de Villalba (1802) y Antonio Almodóvar (1814), entre otros. Además, Antonio Pérez de Escobar y Felipe López Somoza ofrecieron una idea de las investigaciones médicas de finales del siglo ${ }^{88}$.

A lo anterior hay que añadir las traducciones al español que se hicieron de las obras de algunos científicos europeos, que se pueden encontrar en las bibliotecas americanas. Fueron especialmente reveladoras las realizadas por Bartolomé Piñera y Siles de la obra de Le Roux, Disertación acerca de la rabia, y de Cullen, Tratado de la Materia Médica; la de Colombier, Instrucción para precaver la rabia (1786), por Felipe López Somoza; la de Balthasar Sage por Casimiro Gómez Ortega; la de William Buchan, Medicina doméstica, por Pedro Sinnot; o la de Antoine Portal por Hippolyte Jaubert. Tales obras recogían información sobre la enfermedad de otras de importancia como las de Richard Mead, Gerard Van Swieten, Herman Beerheave, Pierre Hunnauld o Giovanni Battista Morgagni.

En aquel ambiente tan sensibilizado a una enfermedad que causaba estragos en Europa no faltaron las aportaciones americanas, habida cuenta de que también comenzaba a desarrollarse de forma alarmante en el continente; incluso en las aulas universitarias se vieron las influencias de algunos autores como Herman Beerhave en Cosme Bueno, profesor en San Marcos de Lima.

88 Pérez de Escobar, Avisos médicos..., 115-127. Felipe López Somoza, prólogo a Instrucción para precaver la rabia y curarla quando está confirmada, de Jean Colombier (Madrid: Imprenta Real, 1786), s/p. 
En el Río de la Plata la problemática favoreció los trabajos expositivos acerca de la enfermedad; así la Memoria de Cristóbal Montúfar sobre los inicios de la epidemia de $1808^{89}$; igualmente es producto de su pluma el Proyecto de informe sobre la representación de don Pedro Martínez o sea el verdadero punto de vista de la medicina curativa de $\mathrm{Mr}$. Le Roy ${ }^{90}$. Justo García Valdés centraría su atención en la casuística, lo mismo que Juan Gutiérrez Moreno, formado en el Colegio de Medicina de Cádiz, que pasó a Montevideo en 1809 y que sería el primer doctorado con una tesis sobre la rabia en la Universidad de Buenos Aires, en $1830^{91}$.

En Nueva España destacaron algunos estudiosos, como José Mariano Mociño, que en su viaje a Guatemala entre 1795-1799 hizo algunos artículos sobre la rabia, analizando la llamada planta "escobosa", considerada como un antídoto y que se aplicaría en el Real Hospital de Puebla por el Dr. Ignacio Domeneche, en 1795, quien escribió Sobre descubrir la verdad antihidrofóbica que tiene la planta Escobosa ${ }^{92}$.

En Perú es de destacar el capítulo de una obra de Unanue, titulado «Influencia del clima sobre los animales», donde se manifiesta como un claro defensor del criollismo, al oponerse a lo mantenido por Buffon y por Jefferson, haciendo un repaso a los brotes rábicos de 1803-1807 en el punto 12 del escrito $^{93}$.

A niveles más generales de la población, la prensa ejercería una mayor influencia, especialmente en las élites letradas, deseosas de obtener información sobre un mal

89 Marcial I. Quiroga, «Los orígenes de la rabia en el Plata: sobre un documento inédito del protomédico Cristóbal Martín de Montúfar fechado en Montevideo en 1808», Boletín de la Academia Nacional de Medicina, nº 52-1 (1974): 103-110.

90 Turnes, Bernardo Porzecanski..., 98.

91 Augusto Soiza Larrosa, «El egresado del Colegio de Medicina de Cádiz Juan Gutiérrez Moreno (1782 -1850)», Salud Militar 35-1 y 2 (2016): 69-80.

92 Miguel Ángel J. Márquez Ruiz, «El intercambio de patógenos,» 80. «Sobre descubrir la verdad antihidrofóbica que tiene la planta Escobosa», Puebla, 1 de septiembre de 1795, Archivo General de la Nación. México (AGN), CDMX-México. Sección Hospitales, Galería 4, Tomo 72, Expediente 11.

93 Unanue, Observaciones..., 59-60 y 67-71 
hasta entonces alejado de su vida y que casi repentinamente pasaba a formar parte de su existencia. Esa prensa, que recogía informaciones científicas de Europa, permitía acceder con mayor inmediatez a la noticia y a las discusiones y proposiciones de los científicos, al mismo tiempo que daba noticias locales y regionales. Es cierto que su información no siempre era la adecuada, como el optimismo que puso el Mercurio Peruano de 2 de febrero de 1792 al jactarse de que aquella enfermedad era una mera especulación; o el Correo de Comercio, de Buenos Aires, que, fundamentándose de una forma equívoca en Bosquillon, criticó el 31 de marzo y el 7 de abril de 1810 las medidas del gobierno bajo el título «Sobre los males que causa la imaginación", alegando que provocaban el temor público, frente a lo recomendado por el galeno francés.

\begin{abstract}
¿Cómo es posible dexar de reconocer el poder de la imaginación en el trastorno que ocasiona en algunas personas el aspecto del cadáver de un rabioso, o la memoria de los tormentos que han sufrido los que se han visto perecer de esta dolencia? Un médico célebre [Temison de Laodicea] sentía en sí las señales que preceden a la rabia cada vez que se acordaba de un amigo suyo que había muerto de hydrophobia a pesar de su esmerada asistencia y cuidado $[\ldots]^{94}$.
\end{abstract}

Aquella intromisión tuvo la respuesta del médico Justo García Valdés, con un folleto en el que reveló la casuística de su trabajo en el Hospital de la Residencia de Buenos Aires y su crítica a los intentos de curar con consejos y sin acción ${ }^{95}$.

Hubo también una prensa metropolitana, que llegaba directamente a las posesiones españolas. Con un carácter oficial pasaba el Semanario de Agricultura y Artes (1797-1808), cuyo destino eran los párrocos, utilizados como transmisores de los avances de la época. En algunos números se trató el tema de la rabia y sus remedios, aunque la casuística era netamente peninsular, lo mismo que en la Gaceta de Madrid y otros periódicos, que esporádicamente podían incluir alguna información ultramarina, como en El Mercurio Histórico o

94 «Beneficencia pública,» Correo de Comercio, Buenos Aires, 7 de abril de 1810.

95 Justo García y Valdés, Carta escrita a los editores del Correo del Comercio de esta ciudad (Buenos Aires: Niños Expósitos, 1810), 1-4. 
en los Anales de Ciencias Naturales, que en un artículo de Antonio José Cavanilles se hacía eco del guaco neogranadino como remedio ${ }^{96}$.

De los periódicos americanos, la Gazeta de México fue la que ofreció mayores informaciones. En Nueva Granada El Censor americano publicaba en septiembre de 1820 que el profesor Lyman Spaldin, de Nueva York, mantenía que la Scutellaria Lateriflora era un buen remedio para la rabia, noticia que reproduciría en mayo de 1842 El correo semanal de Guayaquil. En el Río de la Plata el Correo de Comercio (1810) fue divulgador e informador de la sociedad, en concreto del tema de la rabia.

Toda la información, más o menos científica, acababa por influir en los países hispanoamericanos, aunque a veces las soluciones europeas no respondían a criterios realmente científicos, como los emplastos de pan de nueces, que luego los daban a las gallinas para saber si la herida se podía cerrar ${ }^{97}$; o los baños de mar, que en Francia se aconsejaban en la playa de Dieppe ${ }^{98}$. Se mantenían además otros paliativos tradicionales como el opio, la belladona, las almendras amargas o el vinagre ${ }^{99}$, incluso el ácido clorhídrico.

Otros parecen más adecuados y relacionados con lo reconocido por muchos tratadistas, como cauterizar la herida con hierros candentes o con soluciones de mercurio ${ }^{100}$. Estos remedios tradicionales son los que se aplicaron en los brotes de Lima al "poner un cáustico sobre la parte mordida para promover su supuración y provocar la salivación por medio de las unciones mercuriales» ${ }^{101}$. Tampoco era desacertada la idea de mantener la herida abierta durante 40 días, aplicando

96 Antonio José Cavanilles, «Enfermedad y muerte de un hombre que murió rabioso en los Reales hospitales de esta corte en 1 de febrero de 1801", Anales de Ciencias Naturales 9 (1801): 250-255.

97 Steyneffer, Florilegio medicinal, 383-385.

98 Schneider y Santos-Burgoa, «Tratamiento contra la rabia», 455.

99 Guillermo Cullen, Tratado de la Materia Médica III (Madrid: Benito Cano, 1795), 331 y 459 .

100 Schneider y Burgoa, «Tratamiento contra la rabia», 455.

101 Unanue, Observaciones..., 69. 
además otros remedios, para que no se propagase el veneno. El problema era que muchos remedios europeos difícilmente podían ser aplicados en América, como la hiniesta amarilla que se utilizaba en Ucrania ${ }^{102}$. En la Biblioteca Nacional de Colombia existe un manuscrito que reproduce un remedio copiado del $\mathrm{n}^{\circ} 8$ del Journal des connaissances útiles (1835); en él, se recomienda el aislamiento del enfermo, baños de vapor a $40^{\circ}$ durante siete días, beber zarzaparrilla en las comidas y vino con agua después de ellas, y sudoraciones nocturnas, amén de mucho ejercicio ${ }^{103}$.

No faltaron ideas originales como la utilización del veneno de víbora, recomendado por el dr. Mathiis, cirujano del ejército de Nápoles ${ }^{104}$; o el álcali volátil, fabricado en Madrid por el primer catedrático del Jardín Botánico, Casimiro Gómez Ortega ${ }^{105}$, y cuyo producto vendía Pedro Barrios en México ${ }^{106}$. Incluso todavía en 1864, cuando ya se mantenía que no existía un remedio eficaz, se habló del influjo benéfico de la escuela homeopática ${ }^{107}$.

Frente a las soluciones farmacéuticas europeas, en América se buscaron soluciones en su propia botánica, de los que también hacía eco la prensa, como en Nueva España el "árbol de la margarita o de la flecha», que crecía en Ostotipaquillo y que Martín Sessé mencionó en su carta a Gómez Ortega, en $1785^{108}$; sin olvidar otra planta semejante llamada «hierba colorada» que se daba e Xiquipilco ${ }^{109}$, o la

102 «Hidrofobia,» El centinela, Buenos Aires, 20 de julio de 1823, 44.

103 «Descubrimiento importante,» 647.

104 Vicente Escalera, "Carta al autor de esta», Gazeta de México, México, 6 de octubre de 1784, 479 .

105 Balthasar Georges Sage, Experiencias con que se prueba que el Álkali Volatil fluido... en el mal de rabia (Madrid, Imprenta de la Real Gaceta, 1780). 73-78.

106 «Encargos,» Gazeta de México, México 8 de octubre de 1793, 559-560.

107 Anastasio Álvarez González, Historia Clínica de un caso de rabia declarada (Madrid: Vicente y Lavajos, 1864), 5.

108 Enrique Álvarez López, «Noticias y papeles de la expedición científica mejicana, dirigida por Sessé», Anales del Jardín Botánico de Madrid, no 10-2 (1952): 57-60, acceso el 17 de mayo de 2020, https://revistas.uaz.edu.mx/index.php/adenda/article/ view/117

109 Escalera, «Carta,» 479. «Tepic,» Gazeta de México, México, 22 de febrero de $1785,250-251$. 
cebadilla de Peribán ${ }^{110}$. El amolli, utilizado habitualmente como jabón, también se consideró eficaz para curar la rabia, como lo expresa Carlos Bustamante en las anotaciones a la obra de Sahagún ${ }^{111}$ y como lo propagaron la Gazeta de México, de 3 de octubre de 1807, y el nº 1 del Diario de México, en 1804.

En Nueva Granada se contó con el guaco (Mikania guaco), descubierto en Mariquita en $1788^{112}$. Incluso se habla, sin especificar, del regalo de un americano a un cura italiano de un remedio contra la rabia ${ }^{113}$.

La falta de alarma ante la enfermedad hasta el siglo XVIII es lo que debió evitar la presencia en América de "saludadores» o sanadores que habían aparecido en España en el siglo XVI para curar la rabia con saliva y hasta con el aliento y otros productos, habiendo sido muy criticados por algunos autores como Ciruelo ${ }^{114}$ o en el siglo XVIII por el padre Feijoo ${ }^{115}$; sin embargo, también tuvieron defensores por su tratamiento de la rabia ${ }^{116}$, incluso se contrataban por algunos municipios, especialmente de la mitad norte de la Península, siendo frecuente que tuviesen ciertos problemas con la Inquisición ${ }^{117}$.

La curación de un mal pasaba por algo más que la teoría y los remedios científicos o populares, pues, aunque la política ilustrada trataba de imponer la racionalidad en la sanidad, el pueblo mantenía unas tradiciones vinculadas al ámbito de lo religioso. En ese sentido, la enfermedad era considerada como

110 Probablemente se trate de la cebadilla criolla. Escalera, «Carta,» 479.

111 Bernardino de Sahagún, Historia general de las cosas de Nueva España III (México: Alejandro Valdés, 1830), 244.

112 José María Vergara y Vergara, Historia de la literatura en Nueva Granada II (Bogotá: Banco Popular, 1974), 135-140.

113 «Noticias de Italia,» Mercurio histórico y político, Madrid, diciembre de 1772, 314.

114 Ciruelo, Reprobación..., 94-99.

115 Jerónimo Feijoo, Teatro crítico universal III (Madrid: B. Román, 1781), 1-22.

116 Enrico Martínez, Reportorio de los tiempos y historia natural desta Nueva España (México: Enrico Martínez, 1606), s/p.

117 «Procesos y denuncias a saludadores», Archivo Histórico Nacional de España (AHN), Madrid-España. Sección Inquisición 91-12, 97-1, 3722-240, 3730-356, 3733115, 3735-111. 
un castigo de Dios, y aplacarle era fundamental más allá de las acciones políticas, higiénicas o curativas. No es de extrañar la visión de dos mestizos en México, en la primera década del XVIII, que aludían al envío de enfermedades, como la rabia, para castigar la política del virrey y la mala vida mundana de la corte. Incluso un ilustrado peruano como Unanue llegó a decir que «lo más seguro es matar [a los perros que presentan síntomas], e implorar del padre de las misericordias no vuelva a estos países una calamidad tan acerba ${ }^{118}$.

Por tanto, en el Siglo de las Luces la religión y/o las supersticiones mantenían un valor fundamental ${ }^{119}$. En lo religioso, la invocación directa no se hacía a Dios, sino que se buscaban intercesores como María, ante la cual «la rabia no se embravece» y su «furiosa actividad desespera a la humana medicina $»^{120}$. Entre los protectores contra la hidrofobia destacó Santa Quiteria, que calmaba a los perros con su presencia ${ }^{121}$; por ello, cuando se produjo en México el brote de 1709, inmediatamente se le hizo una novena, reimpresa en 1731 y $1774^{122}$. El autor, el agustino Gil Ramírez, entró en una polémica con el censor franciscano fray Pedro Antonio de Aguirre, porque autorizó la publicación con modificaciones que el primero no quiso aceptar. Apareció entonces la obra titulada El perico y la rabia, burlándose del censor, que presentó una queja ante el Santo Oficio. Al mismo tiempo, Ramírez ponía otra denuncia en el mismo tribunal por la censura de Aguirre a su novena. El resultado fue que la novena se pudo imprimir sin las correcciones sugeridas y que la sátira fue prohibida, aunque no evitó que se siguiese reproduciendo ${ }^{123}$.

118 Unanue, Observaciones..., 71.

119 Osvaldo Antonio Pérez, Historia de la Veterinaria..., 19.

120 Bernardo de Cartes, Historia de la milagrosa imagen de nuestra señora de Monsalud (Alcalá, José Espartosa, 1721), 77-79.

121 Joaquín Lorenzo Villanueva, Año cristiano de España V (Madrid: Imprenta Real, 1792), 384.

122 José Gil Ramírez, Novena de Santa Quiteria virgen, y mártir, patrona de Toledo, abogado de la salud, especial protectora para el mal de rabia (México: Valdés, 1709).

123 Miguel Ángel Jacinto Márquez Ruiz, «Epizootias, zoonosis y epidemias. El intercambio de infecciones y parásitos entre el Viejo y el Nuevo Mundo» (Tesis de doctorado, Universidad de León, 2006), 239-240. Nancy Erika Acuña Aguayo y María Isabel Terán Elizondo, «Los riesgos de censurar libros en la Nueva España del siglo XVIII: Fray Pedro Antonio de Aguirre y la sátira anónima El perico y la rabia. 
También en 1709 fray José de Torrico fue autor de un sermón que se imprimió en acción de gracias por el final de una enfermedad "que comenzó por los brutos y cundió a los racionales», ya que Dios, antes de castigar al mismo hombre, lo hacía en sus cosas ${ }^{124}$. Al año siguiente, se publicó también en México otro sermón a Santa Rita y Santa Quiteria ${ }^{125}$ y, en 1759, se imprimía en Nueva España una novena española de la Santa ${ }^{126}$.

La advocación de santa Quiteria contra la rabia no era la única, puesto que también eran patrones san Huberto, por la curación que hizo de un enfermo, y al que se menciona en la novela de García Márquez como "patrono de los cazadores y sanador de los arrabiados» ${ }^{127}$; santa Walpurga, de cuyo sepulcro se dice que brotaba un líquido curativo; santa Catalina de Alejandría, vinculada a los saludadores; el perro de san Roque, que espantaba a sus congéneres rabiosos; incluso en Costa Rica se recurrió a la protección de Santa Ana ${ }^{128}$.

Todo esto se estaba produciendo en los momentos en que comenzaba a desarrollarse una medicina social, científica y racional en aquellas naciones donde había aparecido un proletariado social, producto de la Revolución Industrial ${ }^{129}$, que en la América hispana ni siquiera tenía atisbos de producirse.

Diálogo entre un médico y un consultor», Adenda Letras Novohispanas, $\mathrm{n}^{\circ} 2-1$ (2016): s/p., acceso el 23 de agosto de 2020, https://tinyurl.com/y6acceqo.

124 José de Torrico Liaño, Sagrada Conjunción de luces en la concurrencia de Sta. Rita y Sta. Quiteria opuestas a la influencia del Can mayor y la Canícula (México: Ribera Calderón, 1709), 1-2 y 5-6. Existe un artículo que menciona este sermón, de Teodoro Carrada Bravo, "Investigación documental de la primera epidemia de rabia registrada en la República Mexicana en 1709», Salud Publica de México, no 6 (1978): 712 .

125 Manuel Pérez, Sermón que en la festividad de Santa Rita y Santa Quiteria el día 22 de mayo de este año de 1710, (México: Nueva Platiniana, 1710).

126 Anónimo, Novena de la gloriosa verge y martir Santa Quiteria que se venera en lo convent de Sanpere de Calanda del Campmajor (México: Imprenta Nueva de la Biblioteca Mexicana, 1759).

127 García Márquez, Del amor, 13, 16, 34.

128 Francisco Guerra, Epidemiología americana y filipina, 1492-1898, (Madrid: Ministerio de Sanidad y Consumo, 1999), 307.

129 Michel Foucault, Obras esenciales. Vol.III: Estética, ética y hermenéutica (Barcelona: Paidós, 1999). 209-215 y Obras esenciales. Vol. IV: Estrategias de poder (Barcelona: Paidós, 1999), 363-384. 


\section{Conclusiones}

La rabia, a pesar del impacto que ejercía por sus síntomas, no ha sido una enfermedad muy tratada por los historiadores, ya que ni en los momentos de mayor desarrollo en América llegó a generar las llamativas visiones de mortandad de otras epidemias; de ahí que con este artículo hayamos tratado de contribuir a llenar un vacío que hasta ahora han tratado casi exclusivamente de llenar médicos y veterinarios, dedicando apenas unas líneas en sus trabajos a los antecedentes históricos. Al mismo tiempo, la rabia o hidrofobia nos ayuda a poner de manifiesto la importancia de la medicina en los estudios de las humanidades, pues, como toda enfermedad, tuvo consecuencias sociales económicas, políticas y culturales.

Seguimos sin poder precisar con claridad la presencia inicial de la rabia en América. Es a partir de los inicios del siglo XVIII cuando se hizo evidente y se extendió con cierta rapidez, generando una alarma social que provocó las matanzas de perros en todo el ámbito hispánico, por considerarlos principales transmisores de la enfermedad. Hubo incluso batidas periódicas en aquellos lugares donde su contención fue más difícil, como el Río de la Plata. Los motivos concretos de aquella eclosión y propagación se nos ocultan, pero sin duda tuvieron que ver con la mejora de los transportes marítimos, que permitían la llegada de animales infectados desde Europa y África, con el incremento del comercio, el traslado de las guerras europeas a América y la mayor movilidad de la población.

Todo esto sucedía en el Siglo de las Luces, coincidiendo con lo que Foucault ha denominado como «biopolítica», es decir, el intervencionismo estatal sobre la vida en general y las enfermedades y su curación en particular para un mayor control sobre la población, ya que interesaba la salud de los individuos en su conjunto (no como individualidades) en función de la utilidad (el poder sobre la vida y el homo o economicus). Esto coincidía en el mundo hispánico, como en Europa, con un momento de crecimiento demográfico y de ampliación de las ocupaciones territoriales, solo posibles a partir de dicho crecimiento (Texas, Florida, Mosquita, Amazonía, Patagonia, 
etc.), además de importantes avances en la medicina, que permitía aumentar los niveles de salud, imprescindibles para los avances económicos y que se tradujeron en campañas de salubridad y de higiene que fueron desde los bandos de buen gobierno a la expansión de la vacuna contra la viruela. Es decir, la monarquía hispánica, como casi todas las del siglo XVIII, mostró su interés por "gestionar la vida" de sus súbditos, incluidos los ultramarinos; es decir, ejercer el «biopoder» del que hablaba el autor francés ${ }^{130}$, aunque con más limitaciones que los monarcas de otras potencias continentales.

De todos modos, en las posesiones españolas ese interés por la salud pública no se manifestó todavía de una forma tan contundente, aunque se aprecia que en los controles de la rabia existieron campañas en las que ya intervinieron directamente las autoridades, incluso recurriendo al ejército, como brazo ejecutor del estado, para paliar su expansión.

Para contener la enfermedad, además, se utilizaron diferentes remedios, algunos de la medicina tradicional, incluso relacionados con la curandería; otros trataron de ser más científicos, y de ellos se daba cuenta en diferentes impresos, aunque su utilidad en la América hispánica no era mucha, ya que solían estar relacionados con las condiciones biológicas de Europa, si bien también se propusieron otros puramente americanos. Ambos encontraron su medio de propaganda a través de la prensa, los libros y los folletos. Precisamente esto pone de manifiesto la decadencia científica del mundo hispánico, que cedía ante los avances de otras naciones, especialmente Francia, cuyos autores eran traducidos sin apenas aportaciones originales, más allá de algunas descripciones y estudios de caso. Casi todos esos tratados coincidían en una visión determinista de la enfermedad, que en este caso se relacionó directamente con el clima seco y caluroso, sin olvidar en otros casos las consideraciones miasmáticas. Las aportaciones americanas apenas tenían eco, probablemente por aquello de los «saberes jerárquicamente

130 Michel Foucault, Historia de la sexualidad 1-La voluntad de saber (México: Siglo XXI, 2007), 169. 
inferiores, saberes por debajo del nivel del conocimiento o de la cientificidad exigidos» en que se consideraba a los extraeuropeos ${ }^{131}$; aun así, hubo aportaciones de remedios que podemos vincular con el criollismo en alza, en la medida en que se trató de poner en valor lo autóctono, especialmente en el campo de la botánica.

Hubo otros remedios más relacionados con la higiene pública, que caracterizaron a la Ilustración: eliminación de perros, limpieza de las calles, higiene personal, etc. Aun hubo ciertos atisbos de desarrollo hospitalario, pero que raramente estaba especializado en esta enfermedad ni en otras, puesto que en el mundo hispánico seguía manteniéndose la idea de lugares de asistencia para pobres y desvalidos de la sociedad, salvo en el caso de algunos hospitales militares, especialmente en las ciudades portuarias.

La rabia, como otras enfermedades, puso de manifiesto que en pleno Siglo de las Luces, conviviendo con los relativos avances de la medicina social en el mundo hispánico, las tradiciones, supersticiones y el peso de las creencias religiosas populares lograban mantenerse vivas, tratando de atajar los males con sermones y novenas a los santos protectores. En este caso, se observa una devoción especial a santa Quiteria. La religión, por tanto, seguía siendo una fuente de esperanza, que no cedía ante la racionalidad, y sus imaginarios eran un paliativo al sufrimiento real, causado por alguna ruptura con la ley divina.

\section{Fuentes documentales}

Archivo General de Indias (AGI), Sevilla-España. Secciones Estado, Indiferente General, Lima, Quito.

Archivo General de la Nación (AGN), Bogotá-Colombia. Secciones Caciques_indios, Criminales-Juicios, Milicias y Marina. Miscelánea.

131 Michel Foucault, Defender la sociedad (México: Fondo de Cultura Económica, 2002), 21. 
Archivo General de la Nación. México (AGN), CDMX-México. Sección Hospitales.

Archivo General de la Nación (AGN), Lima-Perú. Sección Secretaría de Cámara del Virrey.

Archivo Histórico Nacional de España (AHN), Madrid-España. Sección Inquisición.

\section{Fuentes primarias}

Azara, Félix de. Viajes por la América del Sur. Montevideo: Comercio del Plata, 1850.

Boussingault, Jean Baptiste. Memorias. Bogotá: Banco de la República, 1985.

Calvo, Fernando. Libro de Albeyteria: en el qual se trata del cavallo y mulo, y iumento, y de sus miembros y calidades y de todas sus enfermedades. Salamanca: Juan Fernández, 1587.

Canul, Joan. Ritual de los bacbas. Lancaster: Labyrinthos, 2003.

Cárdenas, Juan de. Primera parte de los problemas, y secretos maravillosos de las Indias. México: Pedro Ocharte, 1591.

Ciruelo, Pedro. Reprobaciones a las supersticiones y hechicerías. Valladolid: Maxtor, 2005.

Cullen, Guillermo. Tratado de la Materia Médica. Madrid: Benito Cano, 1795.

Darwin, Charles. Viaje de un naturalista alrededor del mundo. Madrid: Verbum, 2020.

Du Tertre, Jean Baptiste. Histoire generale des Antilles habitées par les françois. París: Thomas Iolly, 1667.

Feijoo, Jerónimo. Teatro crítico universal. Madrid: B. Román, 1781.

Fernández de Oviedo, Gonzalo. Sumario de la natural y general historia de las Indias. México: Fondo de Cultura Económica, 1950. 
Foronda, Valentín de. Cartas sobre la policía. Madrid: Cano, 1801.

García Márquez, Gabriel. Del amor y otros demonios. Buenos Aires: Sudamericana, 1995.

García y Valdés, Justo. Carta escrita a los editores del Correo del Comercio de esta ciudad. Buenos Aires: Niños Expósitos, 1810.

Gil Ramírez, José. Novena de Santa Quiteria virgen, y mártir, patrona de Toledo, abogado de la salud, especial protectora para el mal de rabia. México: Valdés, 1709.

Juan, Jorge, y Antonio de Ulloa. Relación histórica del viaje a la América Meridional. Madrid: Antonio Marín, 1748.

Larrañaga, Dámaso Antonio. Diario del viaje de Montevideo a Paysandu. Montevideo: Instituto Nacional del Libro, 1994.

López de Gómara, Francisco. Historia general de las Indias. Caracas: Ayacucho, 1979.

López Somoza, Felipe. Prólogo a Instrucción para precaver la rabia y curarla quando está confirmada, de Jean Colombier, s/p. Madrid: Imprenta Real, 1786.

Martínez, Enrico. Reportorio de los tiempos y historia natural desta Nueva España. México: Enrico Martínez, 1606.

Pérez, Manuel. Sermón que en la festividad de Santa Rita y Santa Quiteria el día 22 de mayo de este año de 1710. México: Nueva Platiniana, 1710.

Pérez de Escobar, Antonio. Avisos médicos, populares, y domésticos. Historia de todos los contagios. Madrid: Ibarra, 1776.

Sage, Balthasar Georges. Experiencias con que se prueba que el Álkali Volatil fluido es el remedio más eficaz en las asphyxias o muertes aparentes de los ahogados y sofocados del tufo del carbón etc. con varias observaciones... en el mal de rabia. Madrid: Imprenta de la Real Gaceta, 1780.

Sahagún, Bernardino de. Historia general de las cosas de Nueva España. México: Alejandro Valdés, 1830. 
Steyneffer, Juan de. Florilegio medicinal. Amsterdam: Oosterwiyck, 1719.

Sydeham, Thomas. Praxis Médica. Londres: Kneps e Innys, 1716.

Torrico Liaño, José de. Sagrada Conjunción de luces en la concurrencia de Sta. Rita y Sta. Quiteria opuestas a la influencia del Can mayor y la Canícula. México: Ribera Calderón, 1709.

Vives, Francisco Dionisio. Bando de buen gobierno adicionado. La Habana: Fraternal, 1828.

Vives, Francisco Dionisio. «Bando de buen gobierno, adicionado por el excelentísimo señor...». En Los bandos de buen gobierno en Cuba: la norma y la práctica (1730-1840), editado por Dorleta Apaolaza Llorente 568. Vitoria: Universidad del País Vasco, 2016.

Vives, Francisco Dionisio. Cuadro estadístico de la siempre fiel isla de Cuba, correspondiente al año de 1827. La Habana: Oficina de las viudas de Arazoza y Soler, 1829.

Zinke, Georg Gottfried. Neue Ansichten der Hundswut. Jena: Fisher, 1804.

\section{Fuentes hemerográficas}

«Beneficencia pública». Correo de Comercio, Buenos Aires, 7 de abril de 1810.

«Descubrimiento importante». Gaceta de México, México, 3 de octubre de 1807.

«Encargos». Gazeta de México, México, 8 de octubre de 1793, 559-560

Escalera, Vicente. "Carta al autor de esta.» Gazeta de México, México, 6 de octubre de 1784 .

«Gran Bretaña». Gaceta de Madrid, Madrid, 26 de octubre de 1819.

«Hidrofobia». El centinela, Buenos Aires, 20 de julio de 1823. 
«Noticias de Italia». Mercurio histórico y político, Madrid, diciembre, 1772 .

«Rabia». La Abeja Argentina, Buenos Aires, 15 de mayo de 1822.

«Resumen de los enfermos que entran a curarse en el Hospital General de San Pedro Apóstol». Gazeta de México, México, 13 de marzo de 1802.

François Rozier, «De la rabia». Semanario de Agricultura, Madrid, 29 de noviembre de 1798.

«Tepic». Gazeta de México, México, 22 de febrero de 1785.

\section{Fuentes secundarias}

Acuña Aguayo, Nancy Erika, y María Isabel Terán Elizondo. «Los riesgos de censurar libros en la Nueva España del siglo XVIII: Fray Pedro Antonio de Aguirre y la sátira anónima El perico y la rabia. Diálogo entre un médico y un consultor». Adenda Letras Novohispanas, $\mathrm{n}^{0}$ 2-1 (2016): 1-33. Acceso el 17 de julio de 2020. https://revistas.uaz.edu.mx/index.php/adenda/ article/view/117.

Álvarez González, Anastasio. Historia Clínica de un caso de rabia declarada. Madrid: Vicente y Lavajos, 1864.

Álvarez López, Enrique. "Noticias y papeles de la expedición científica mejicana, dirigida por Sessé». Anales del Jardín Botánico de Madrid, $\mathrm{n}^{\circ}$ 10-2 (1952): 5-79. Acceso el 17 de mayo de 2020. https://revistas.uaz.edu.mx/index.php/adenda/ article/view/117.

Alzate Echeverri, Adriana María. Suciedad y orden: reformas sanitarias borbónicas en la Nueva Granada 1760-1810. Bogotá: Universidad del Rosario, 2007.

Anónimo. Novena de la gloriosa verge y martir Santa Quiteria que se venera en lo convent de Sanpere de Calanda del Campmajor. México: Imprenta Nueva de la Biblioteca Mexicana, 1759.

Anónimo, «Siglo XVIII (1701-1750). Panorama histórico dominante». Cuadernos de Historia de la Salud Pública, n 96 
(2004): sp. Acceso el 4 de septiembre de 2020, https://tinyurl. com/y44yts24.

Babes, Victor. Traité de la rage. París: Bailliere et fils, 1912.

Badrane, H., y N. Tordo. «Host switching in Lyssavirus history from the Chiroptera to the Carnivora orders». Journal of Virology, no 75 (2001): 8096-8104. Doi: https://doi.org/10.1128/ JVI.75.17.8096-8104.2001.

Beltrán, José Luis. Historia de las epidemias: en España y sus colonias (1348-1919). Madrid: Esfera de los Libros, 2006.

Bergasse, Nicolas. Lettre d’un médecin de la Faculté de Paris à un médecin du Collège de Londres. La Haya: Drukarz Nieznany, 1781.

Brejov, Gregorio Daniel. «Perros de los conquistadores y cimarrones». Revista Veterinaria Argentina (abril 2020): 1-3. Acceso el 29 de julio de 2020. https://www.veterinariargentina.com/ revista/2020/04/perros-de-los-conquistadores-y-cimarrones/

Bueno Jiménez, Alfredo. «Los perros en la conquista de América: historia e iconografía». Chronica Nova, no 37 (2011): 177204. Acceso el 18 de abril de 2020. http://hdl.handle. net/10481/20359.

Carlos Francisco Amasino, C. J. Garbi, y M. F. Amasino. «La rabia urbana en la provincia de Buenos Aires, Argentina: origenevolución-actualidad». Analecta Veterinaria, no 22-1 (2002): 17-31. Acceso el 12 de marzo de 2021. http://sedici.unlp.edu. ar/handle/10915/11141.

Carrada Bravo, Teodoro. «Investigación documental de la primera epidemia de rabia registrada en la República Mexicana en 1709». Salud Publica de México, nº 6 (1978): 705-716.

Cartes, Bernardo de. Historia de la milagrosa imagen de nuestra señora de Monsalud. Alcalá: José Espartosa, 1721.

Cavanilles, José Antonio. «Enfermedad y muerte de un hombre que murió rabioso en los Reales hospitales de esta corte en 1 de 
febrero de 1801». Anales de Ciencias Naturales, no 9 (1801): 250-255.

Cordero del Campillo, Miguel. Crónicas de Indias. Ganadería, medicina y veterinaria. Valladolid: Junta de Castilla y León, 2001.

Cordero-Moreno, Rafael. Compendio de la historia de la medicina en Venezuela. Caracas: Universidad Católica Andrés Bello, 1998.

Diego, Alberto I. de, y Jorge R. Valotta. «Rabia transmitida por murciélagos». Boletín de la Oficina Sanitaria Panamericana, $n^{\circ}$ 86-6 (1979): 495-508. Acceso el 18 de junio de 2020. https:// iris.paho.org/handle/10665.2/17296.

Escobar, Elmer. «La rabia transmitida por vampiros». Biomédica vol. $24, \mathrm{n}^{\circ} 3$ (2004): sp. Doi: https://doi.org/10.7705/biomedica. v24i3.1268.

Exbalin Oberto, Arnaud. «Perros asesinos y matanzas de perros en la ciudad de México (siglos XVI-XVIII». Relaciones, $\mathrm{n}^{\circ} 137$ (2014): 91-111.

Foucault, Michel. «Historia de la medicalización». Educación médica $y$ salud, $\mathrm{n}^{\circ}$ 11-1 (1977): 3-25. Acceso el 17 de junio de 2020. https://www.terceridad.net/Sistemasdesalud/Foucault, $\% 20$ M.\%20Historia\%20de\%20la\%20medicalizaci\%F3n.pdf.

Foucault, Michel. «Incorporación del hospital en la tecnología moderna». Educación médica y salud, n $12-1$ (1978): 20-36.

Foucault, Michel. «La crisis de la medicina o la crisis de la antimedicina». En Medicina e historia. El pensamiento de Michel Foucault, editado por Miguel Márquez, 17-35. Washington: Organización Panamericana de la Salud, 1978.

Foucault, Michel. Obras esenciales. Vols. I-IV: Estrategias de poder. Barcelona: Paidós, 1999.

Foucault, Michel. Defender la sociedad. México: Fondo de Cultura Económica, 2002. 
Foucault, Miche. Seguridad, territorio, población. México: Fondo de Cultura Económica, 2006.

Foucault, Michel. Historia de la sexualidad 1-La voluntad de saber. México: Siglo XXI, 2007.

Foucault, Michel. Nacimiento de la biopolítica: Curso del Collège de France (1978-1979). Barcelona: Akal, 2012.

Garcés, Enrique. Eugenio Espejo, médico y duende. Quito: Casa de la Cultura Ecuatoriana, 1959.

Guerra, Francisco. Epidemiología americana y filipina, 1492-1898. Madrid: Ministerio de Sanidad y Consumo, 1999.

Johnson, Harald Norlin. «Rabies». En Viral and Rickettsial Infections of Man, editado por Thomas M. Rivers y Frank L.Horsfall Jr., 17-18. Filadelfia: Lippincott, 1959.

King, A.A., A.R. Fooks, M. Aubert, y A.I. Wandeler. Historical Perspective of Rabies in Europe and the Mediterranean Basin. A testament to rabies by Dr Arthur A. King. Paris: World Organisation for Animal Health, 2004.

Larrañaga, Dámaso Antonio. Diario del viaje de Montevideo a Paysandu. Montevideo: Instituto Nacional del Libro, 1994.

López de Gómara, Francisco. Historia general de las Indias. Caracas: Ayacucho, 1979.

López Somoza, Felipe. Prólogo a Instrucción para precaver la rabia y curarla quando está confirmada, de Jean Colombier, s/p. Madrid: Imprenta Real, 1786.

Málaga Alba, Aurelio. «Vampire bat as a carrier of rabies» American Journal of Public Health, $\mathrm{n}^{\circ} 44$ (1954): 909-918.

Marmolejo, Lucio. Efemérides guanajuatenses, o, datos para formar la historia de la ciudad de Guanajuato. Guanajuato: Universidad de Guanajuato, 1971.

Márquez Ruiz, Miguel Ángel Jacinto. «Epizootias, zoonosis y epidemias. El intercambio de infecciones y parásitos entre el 
Viejo y el Nuevo Mundo». Tesis de doctorado, Universidad de León, 2006.

Márquez Ruiz, Miguel Ángel. «El intercambio de patógenos entre el Viejo y el Nuevo Mundo, los casos de la rabia y del moquillo canino". Revista del Colegio de Médicos Veterinarios del estado Lara, $\mathrm{n}^{\circ}$ 1-2 (2011): s/p. Acceso el 25 de mayo de 2020. https:// dialnet.unirioja.es/servlet/articulo?codigo $=3885625$

Martínez-Fortún Foyo, José A. Epidemiología: síntesis cronológica. La Habana: Ministerio de Salubridad, 1952.

Molina Solís, Gonzalo. Historia del descubrimiento y conquista del Yucatán. Mérida de Yucatán: Mensaje, 1943.

Morros, Bienvenido. «Amor y rabia en una novela de Gabriel García Márquez». Revista de Filología, n ${ }^{\circ} 26$ (2008): 167-179. Acceso el 15 de junio de 2020. http://riull.ull.es/xmlui/handle/915/14203.

Nadin-Davis, S.A., y J. Bingham. «Europe as a Source of Rabies for the Rest of the World». En Historical Perspective of Rabies in Europe and the Mediterranean Basin, editado por A.A. King, A.R. Fooks, M. Aubert y A.I. Wandeler, 259-280. París: World Organisation for Animal Healt, 2004.

Pérez, Osvaldo Antonio. «Ciencia y superstición. Los tratamientos contra la rabia en Sudamérica a fines del siglo XIX». Bitácora-e, $\mathrm{n}^{\circ} 1$ (2011): 56-64.

Pérez, Osvaldo Antonio. Historia de la Veterinaria en el Río de la Plata. Buenos Aires: El Plata, 1994.

Pérez Baltasar, María Dolores. «Buenos Aires, un ejemplo de urbanismo ilustrado». Tesis de doctorado, Universidad Complutense de Madrid, 2015.

Piñera y Siles, Bartolomé. Discurso del traductor a Disertación acerca de la rabia espontánea, de Laurent Charles Pierre Le Roux, 1-30. Madrid: José Doblado, 1786.

Quevedo, Francisco de. Poesía metafísica y amorosa. Barcelona: Planeta, 1976. 
Quiroga, Marcial I. «Los orígenes de la rabia en el Plata: sobre un documento inédito del protomédico Cristóbal Martín de Montúfar fechado en Montevideo en 1808». Boletín de la Academia Nacional de Medicina, nº 52-1 (1974): 103-110.

Rodríguez Dobles, Enrique. «Discordias teóricas de la historia de las mentalidades colectivas, aportes, conceptos y problemas». Reflexiones, $\mathrm{n}^{\circ}$ 84-1 (2005): 7-20.

Rodríguez Ferri, Elías Fernando. Rabia, riesgos y control. Análisis de la situación en España. Madrid: Consejo General de Colegios Veterinarios, 2014.

Salamanca, Bartolomé María. "Arequipa. Relación de Gobierno». Boletín de la Sociedad Geográfica de Lima, nº 10 (1901): 207-236.

Salcedo Chirinos, César Augusto. «El perro como problema sanitario: Higiene y gobierno urbano en el Puerto Rico del siglo XIX». Revista de Ciencias y Humanidades, $\mathrm{n}^{\circ}$ 1010 (2020): 255-275. Acceso el 18 de junio de 2020. https:// revistacienciasyhumanidades.com/index.php/home/article/ view/112.

Schneider, María Cristina, y Carlos Santos-Burgoa. «Tratamiento contra la rabia humana: un poco de su historia». Revista de Saúde Pública, nº 28-6 (1994): 454-457.

Soiza Larrosa, Augusto. «El egresado del Colegio de Medicina de Cádiz Juan Gutiérrez Moreno (1782 -1850)». Salud Militar, n ${ }^{\circ}$ 35-1 y 2 (2016): 69-80.

Tau Anzoátegui, Víctor. Los bandos de buen gobierno del Río de la Plata, Tucumán y Cuyo: (época hispánica). Buenos Aires: Instituto de Investigaciones de Historia del Derecho, 2004.

Torres Guevara, Juan. «El clima y los ecosistemas». En Historia ambiental del Perú. Siglos XVIII y XIX, editado por Julio Díaz Palacios, Martín Arana Cardó, Juan Torres Guevara y Sandro Patrucco Núñez-Carvallo, 91-110. Lima: Ministerio del Ambiente, 2016. 
Turnes, Antonio L. Bernardo Porzecanski y su lucha contra la rabia en el Uruguay. Montevideo: Granda, 2014.

Unanue, Hipolito. Observaciones sobre el clima de Lima, y sus influencias en los seres organizados, en especial el hombre. Madrid: Imprenta de Sancha, 1815.

Valdés, Rodrigo de. Poema heroyco hispano-latino panegyrico de la fundación, y grandezas de la muy noble, y leal ciudad de Lima. Madrid: Antonio Romás, 1687.

Vergara y Vergara, José María. Historia de la literatura en Nueva Granada. Bogotá: Banco Popular, 1974.

Villanueva, Joaquín Lorenzo. Año cristiano de España V. Madrid: Imprenta Real, 1792.

Vos, A., C. Numan, D, Bolles, T. Müller, A. R. Fooks, N. Tordo y G. M. Bear. "The occurrence of rabies in pre-Columbian Central America: an historical search». Epidemiology and Infection, $\mathrm{n}^{\circ} 10$ (2011): 1445-1452. Doi: dx.doi.org/10.1017/ S0950268811001440.

\section{Sitios web}

Habana Elegante. «Marqués de Armas, Pedro L. Panóptico habanero». Acceso el 18 de junio de 2020. http://www.habanaelegante. com/Winter2004/Panoptico.html.

Revisionistas. La otra historia de los argentinos. «Perros cimarrones». Acceso el 27 de febrero de 2020. http://www.revisionistas.com. $\operatorname{ar} / ? \mathrm{p}=7429$.

\section{Citar este artículo}

Paniagua Pérez, Jesús. "La rabia en América durante el dominio español, S. XVI-XVIII». Historia Y MEMORIA, $\mathrm{n}^{\circ} 23$ (2021): 57-96. Doi: https:/doi.org/10.19053/20275137. $\mathrm{n} 23.2021 .11807$. 